\title{
A comparison of the chemical characteristics of oceanic DOM and extracellular DOM produced by marine algae
}

\author{
L. I. Aluwihare*, D. J. Repeta \\ Woods Hole Oceanographic Institution, Woods Hole, Massachusetts 02543, USA
}

\begin{abstract}
The chemical characteristics of extracellular high molecular weight (HMW) dissolved organic matter (DOM) from 3 species of marine phytoplankton were compared to HMW DOM in seawater. Thalassiosira weissflogij, Emiliania huxleyi and Phaeocystis sp., were grown in nutrient enriched seawater that had been previously ultrafiltered to remove HMW DOM. The extracellular HMW DOM produced in these cultures was isolated by ultrafiltration and characterized using nuclear magnetic resonance (NMR) spectroscopy, and molecular level analyses. All species exude DOM rich in polysaccharides, and the exudates of $T$ weissflogii and $E$. huxleyi closely resemble acyl heteropolysaccharides (APS) previously identified as major constituents of naturally occurring marine HMW DOM. Degradation of the $T$. weissflogii exudate alters the chemical composition of the DOM, which we attribute to differences in the reactivity of specific polysaccharides. The component within the exudate that most resembles seawater DOM has a slower degradation rate relative to the total polysaccharide fraction. Our study indicates that APS isolated from the surface ocean can have a direct algal source and that APS may accumulate in seawater as a result of its metabolic resistance.
\end{abstract}

KEY WORDS: Thalassiosira weissflogii Emiliania huxleyj - Phaeocystis - Dissolved organic matter Polysaccharides · Nuclear magnetic resonance

\section{INTRODUCTION}

Dissolved organic matter (DOM) in the ocean is a byproduct of marine primary production (Williams \& Gordon 1970, Mague et al. 1980, Carlson \& Ducklow 1995). Several processes may act to transfer organic matter from plankton to seawater, for example: direct exudation by phytoplankton (Fogg 1962, 1966, 1971, Hellebust 1965, Mague et al. 1980, Jensen 1983, Baines \& Pace 1991) and heterotrophs (Nagata \& Kirchman 1992, Tranvik 1994, Tanoue 1995, Stoderegger \& Herndl 1998), indirect production through 'sloppy feeding' (Lampert 1978), dissolution of fecal pellets, marine snow (Alldredge et al. 1993) or other marine aggregates, and cell lysis (Fuhrman 1992). While all of these processes have been shown to occur, there is little data that directly links the DOM released by these mechanisms to DOM which accumulates in seawater. Thus, we do not yet understand how the process of DOM

•E-mail: laluwihare@whoi.edu introduction may affect its ultimate fate. For example, DOM that is directly released by plankton may be more labile than reworked DOM introduced by grazing. Using ${ }^{13} \mathrm{C}$-labeled bicarbonate in a mesocosm experiment, Norrman et al. (1995) induced a mixed algal bloom, dominated by diatoms, and stimulated the release of DOM. Bacteria preferentially utilized labeled DOM, suggesting that newly synthesized DOM is labile, however, a fraction of the labeled DOM persisted after 1 yr of incubation. By using stable isotopes, Norrman et al. (1995) were able to quantify recently synthesized DOM, and trace its production, accumulation and utilization. However, the dynamics of labeled DOM alone do not show if the long lived fraction of DOM was directly produced by phytoplankton, or resulted from a reworking of the extracellular DOM by bacteria. It was also not determined if the experimentally produced DOM was chemically related to DOM that accumulates in seawater.

We have recently shown that the fraction of oceanic DOM retained by a $1 \mathrm{kD}$ (nominal molecular weight) 


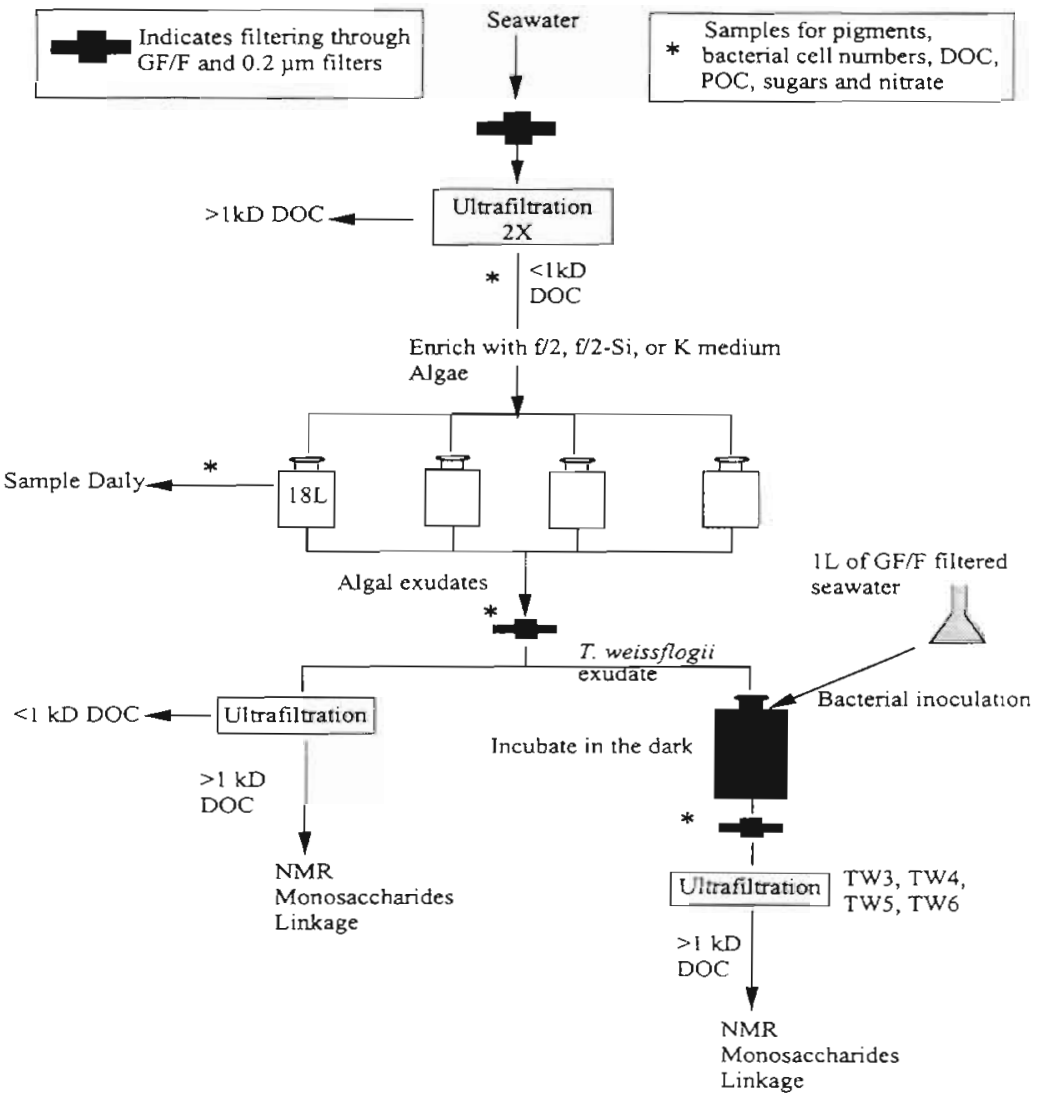

Fig 1. Experimental set up for the culture experiments. Seawater was ultrafiltered to remove HMW DOM as shown. Both the Emiliania huxleyi and Phaeocystis experiments were terminated after the algae were removed without further degradation of the exudate. TW3, TW4, TW5 and TW6 refer to samples taken during the degradation of the Thalassiosira weissflogii exudate (dates are given in Fig. 2)

ultrafiltration membrane (hereafter HMW DOM), is rich in acyl heteropolysaccharides (APS) which have a characteristic acetate:carbohydrate:lipid ratio (Aluwihare et al. 1997). The carbohydrate fraction of APS contains at least 7 major neutral monosaccharides which occur in a relatively fixed ratio and which are linked together at specific positions. High molecular weight DOM with a similar distribution of neutral monosaccharides has been isolated from geographically diverse locations (Sakugawa \& Handa 1985. McCarthy et al. 1996, Aluwihare et al. 1997, Borch \& Kirchman 1997, Skoog \& Benner 1997), which together with our structural data led us to conclude that a large fraction of persistent DOM in seawater is produced by direct algal biosynthesis.

The present study investigates the HMW fraction of extracellular DOM produced in laboratory cultures of 3 algal species, Thalassiosira weissflogii, a diatom, Emiliania huxleyi sp., and Phacocystis sp., both prymnesiophytes. These algae were chosen to represent classes of phytoplankton important in oceanic primary production, and because previous laboratory studies have shown that the extracellular DOM produced by these phytoplankton is rich in carbohydrates. $T$. weissflogii and other diatoms are abundant in both coastal and ocean open areas; E. huxleyi is a cosmopolitan algae and a major contributor to primary production in the open ocean, and Phaeocystis sp. are mucus producing algae important in high latitude environments. The extracellular DOM isolated from each culture was studied in extensive chemical detail in order to determine which algae could be a potential source for APS isolated from the surface ocean. Our data show that all 3 species do indeed exude DOM in culture and that 20 to $30 \%$ of the extracellular DOM from both $T$. weissflogii and E. huxleyi is spec. trometrically and chemically similar to APS isolated from surface seawater. Furthermore, degradation of the $T$. weissflogii exudate shows that APS is metabolically more resistant to degradation than other polysaccharides.

\section{METHODS}

Phytoplankton cultures. All algae grown for this study were obtained from the Center for Culturing Marine Phytoplankton (CCMP), at Bigelow Laboratory, in Boothbay Harbor, ME. Species include Thalassiosira weissflogii (CCMP 1336), Phaeocystis sp. (CCMP 628), and Emiliania huxleyi (CCMP 373) $T$. weissflogii and E. huxleyi were obtained as axenic seed cultures. The seawater used for the $T$. weissflogii was collected from a depth of $1000 \mathrm{~m}$, south of Nantucket Island, MA $\left(39^{\circ} 49^{\prime} \mathrm{N}, 70^{\circ} 20^{\prime} \mathrm{W}\right)$, and the seawater used for E. huxleyi, and Phaeocystis sp. was collected in Great Harbor, Vineyard Sound, Woods Hole, MA. All seawater was prefiltered $(0.2 \mu \mathrm{m})$ and ultrafiltered twice to remove high molecular weight ( $>1 \mathrm{kD}$ ) dissolved organic carbon (HMW DOC). Prior to adding $T$. weissflogii, seawater was enriched with nutrients, vitamins and trace metals added as $\mathrm{f} / 2$ concentrations according to Guillard \& Ryther (1962), with an additional enrichment of sodium selenite $\left(\mathrm{NaSeO}_{3}\right)$ to a final concentration of $10^{-8} \mathrm{M}$. In the case of $E$. huxleyi, the media was enriched with $\mathrm{f} / 2$-Si medium (Guillard \& Ryther 1962), and Phaeocystis sp. was grown in $\mathrm{K}$ medium (Keller et al. 1987). Care was taken to keep 
bacterial populations low throughout the experiment by sterilizing all culture and sampling apparatus. A flow diagram of the experimental set up is shown in Fig. 1. T. weissflogii and E. huxleyi were grown at $23^{\circ} \mathrm{C}$, in 18 l glass carboys which were continuously aerated, and illuminated at $900 \mu \mathrm{E} \mathrm{m}^{-2} \mathrm{~s}, 24: 0 \mathrm{~h} \mathrm{L:D}$ (light:dark) and 14:10 h L:D, respectively. The cultures were sampled daily for particulate organic carbon (POC), DOC, chlorophyll a (chl a), nutrients and cell numbers. Phaeocystis sp. was grown in an $18 \mathrm{l}$ glass carboy, at $26^{\circ} \mathrm{C}$ in an incubator on a $14: 10 \mathrm{~h} \mathrm{~L}$ :D cycle, by Dr Steven Morton at the CCMP. The $T$. weissflogii culture was harvested during late log phase growth determined by previous culture experiments and chl a absorbance. E. huxleyi and Phaeocystis were also harvested during late log phase growth, based on chl a absorbance and cell counts, respectively. All algae were removed by filtering (Whatman GF/F) and the exudates isolated as shown in Fig. 1.

Subsamples $(9 \mathrm{ml})$ for counting bacterial and phytoplankton cells (Emiliana huxleyi) were collected daily, preserved with $1 \mathrm{ml}$ of $10 \%$ glutaraldehyde and stored at $4^{\circ} \mathrm{C}$. Samples were filtered onto blackened Nuclepore $0.2 \mu \mathrm{m}$ polycarbonate filters and stained using a final concentration of $0.005 \% \mathrm{v} / \mathrm{v}$ acridine orange (Hobbie et al. 1977). Five vertical and horizontal fields were counted for each slide using a standard Zeiss microscope with epifluorescence microscopy. The microscope was fitted with a bandpass 450-490 exciter, a FT510 chromatic beam splitter and a LP520 barrier filter. Bacterial cell numbers were converted to carbon using a conversion factor of $20 \mathrm{fg} \mathrm{C} \mathrm{cell}^{-1}$ (Lee \& Fuhrman 1987).

The cultures were monitored daily for chl a concentrations by filtering 15 to $45 \mathrm{ml}$ of the culture medium onto Whatman GF/F filters, extracting with $100 \%$ acetone, and measuring the absorbance at $664 \mathrm{~nm}$. Conversion from absorbance to concentration was achieved assuming an extinction coefficient $(\varepsilon)$ of $8 \times$ $10^{5} \mathrm{M}^{-1} \mathrm{~cm}^{-1}$. POC analyses were performed according to the acidification method of Hedges (1991). Culture samples $(20 \mathrm{ml})$ were filtered onto precombusted Whatman GF/F filters and frozen $\left(-20^{\circ} \mathrm{C}\right)$ until analysis ( 1 to $6 \mathrm{mo}$ ). Prior to analysis, filters were oven dried overnight at $60^{\circ} \mathrm{C}$, exposed to $\mathrm{HCl}$ vapors in a desiccator under vacuum (in the case of Emiliana huxleyi acidified with $100 \mu \mathrm{l}$ of $2 \mathrm{~N} \mathrm{HCl}$ ), and oven dried again, overnight at $60^{\circ} \mathrm{C}$. After acidification, the filters were subsampled for triplicate analysis of carbon, nitrogen and hydrogen using a Fisons automated elemental analyzer.

The filtrates from the POC samples were collected in combusted vials fitted with Teflon-lined caps, acidified with $50 \% \mathrm{H}_{3} \mathrm{PO}_{4}\left(5 \mu \mathrm{H}_{3} \mathrm{PO}_{4} \mathrm{ml}^{-1}\right)$, and stored at room temperature or at $4^{\circ} \mathrm{C}$. The samples were analyzed for DOC by high temperature catalytic oxidation (Peltzer \& Brewer 1993). Precision for triplicate analyses was
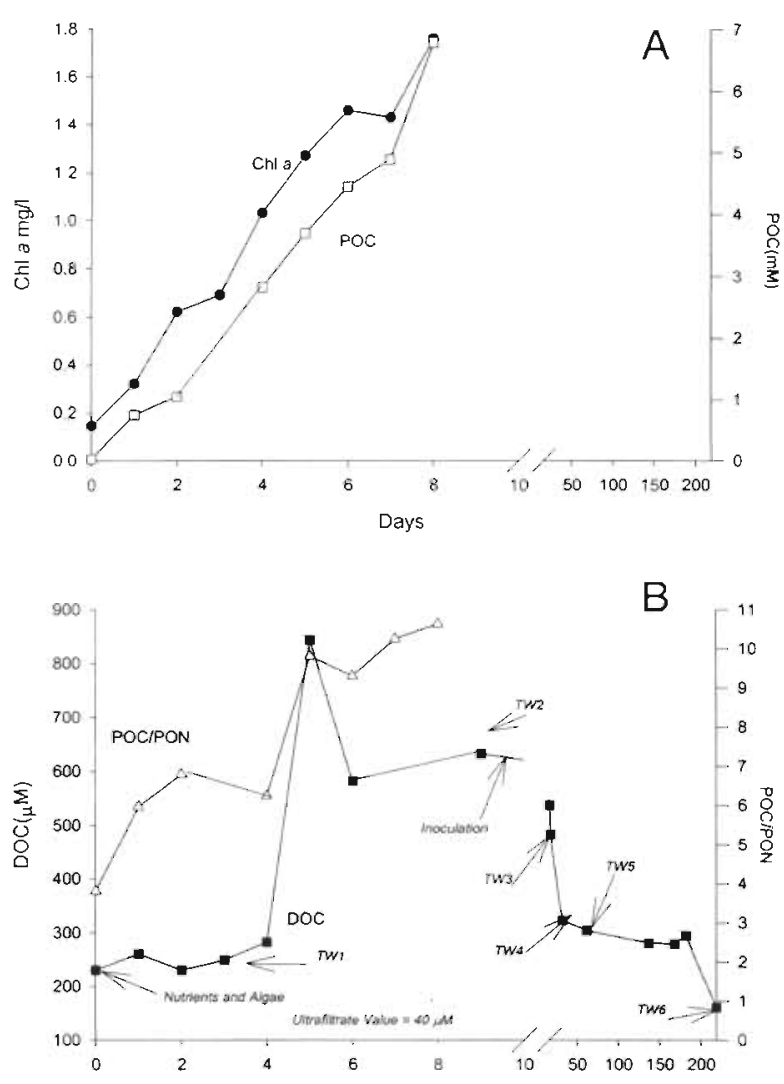

Fig. 2. Thalassiosira weissflogii culture ancillary data. (A) Changes in chl a (•) and POC (D). (B) Changes in the DOC concentration $(\square)$ and $\mathrm{C} / \mathrm{N}$ ratios of the POC $(\Delta)$. Algae were removed on Day 8. TW1 refers to the ultrafiltration sample taken during early log phase, TW2 was taken during late log phase, and TW $3,4,5$ and 6 were taken during the course of the degradation experiment after the algae had been removed. After Day 9, changes in DOC concentration result from the action of microorganisms present in the incubation, or from physical removal mechanisms

better than $\pm 3.5 \%$, and the upper limit for our system blank was $20 \mu \mathrm{M}$, based on the DOC concentration of our acidified carbon-free distilled water.

The Thalassiosira weissflogii exudates, isolated from the five carboys at the end of the experiment (Day 8 in Fig. 2), were combined ( 80 l), filtered and subjected to microbial degradation. The degradation was initiated by inoculating the exudate with 11 of prefiltered (Whatman GF/F) Woods Hole seawater. Following inoculation, the exudate was incubated in the dark for 8 mo to monitor compositional changes in the DOC due to microbial degradation. Samples were taken periodically for ultrafiltration, concentration measurements, and bacterial cell counts

Ultrafiltration. Cultures were filtered through a precombusted Whatman GF/F filter and a pre-rinsed $0.2 \mu \mathrm{m}$ polysulphone cartridge filter, and ultrafiltered to isolate the HMW DOM using an Amicon DC-10L 
system equipped with 2 spiral wound polysulphone filter membranes ( $1 \mathrm{~nm}$, nominally $>1 \mathrm{kD}$ ). Eight to $10 \mathrm{l}$ were ultrafiltered for each of the Thalassiosira weissflogii samples, and 141 were ultrafiltered for the Emiliana huxleyi and Phaeocystis sp. samples. Samples were concentrated to approximately $1 \mathrm{l}$ and diafiltered $(10 \times)$ using 2 l each of de-ionized (Milli-Q) water. Permeate from the final Milli- $Q$ rinse no longer gave a visible precipitate when added to a solution of silver

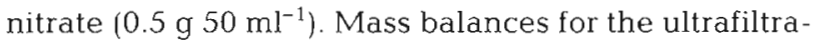
tion were $95 \pm 15 \%$. High molecular weight DOM concentrates were stored frozen in glass or Teflon bottles and lyophilized prior to analysis.

Analyses. Proton Nuclear Magnetic Resonance $\left({ }^{1} \mathrm{HNMR}\right)$ spectrometry was performed on the HMW DOM fraction using a Bruker AC300 spectrometer. Between 2 and 5 mg of HMW DOM were dissolved in $\mathrm{D}_{2} \mathrm{O}$ (deuterium oxide) and freeze dried. This procedure was repeated ( 2 to 3 times) to reduce the $\mathrm{H}_{2} \mathrm{O}$ content. All spectra were acquired with presaturation of the HDO (partially deuterated water) peak (4.8 ppm), and chemical shifts are reported using standard $\delta$ notation (ppm).

The neutral monosaccharide composition of the HMW DOM fraction was determined according to York et al. (1985). Briefly, the hydrolysis of the polysaccharides was carried out by heating a mixture of 300 to $700 \mu \mathrm{g}$ of dry sample in $0.5 \mathrm{ml}$ of $2 \mathrm{M}$ trifluoroacetic acid (TFA), containing $20 \mu \mathrm{g}$ of myo-inositol as an internal standard, at $121^{\circ} \mathrm{C}$ for $2 \mathrm{~h}$ in a sealed reaction tube. Monosaccharides were reduced to alditol acetates using sodium borohydride $\left(\mathrm{NaBH}_{4}\right)$. Alditols were per-acetylated with acetic anhydride, and 1methyl imidazole. The alditol acetates, dissolved in methanol, were analyzed using an HP 5890 gas chromatograph equipped with a $30 \mathrm{~m}$, DB-5 fused silica column $(0.25 \mathrm{~mm}$ ID, and $0.20 \mu \mathrm{m}$ film), using a temperature program of $150(1) / 2 / 240(15)$, (initial temp.(time)/ramp/final temp.(time)).

The pattern of monosaccharide linkages within the polysaccharides in HMW DOM was determined by carbohydrate linkage analysis. Samples were prepared as partially methylated alditol acetates according to the method of Hakomori (1964), with a few modifications. Freeze dried samples were first desalted by applying the sample, dissolved in water $\left(1.5 \mathrm{meq} \mathrm{ml}^{-1}\right.$ of resin bed), to a cation exchange resin (BioRad $A G$ $50 \mathrm{~W}-\mathrm{X} 8$ ) in the hydrogen form and eluting with water ( 3 column bed volumes). Up to $1 \mathrm{mg}$ of the desalted, dry sample was dissolved in $0.5 \mathrm{ml}$ of dry dimethylsulphoxide (DMSO) under nitrogen with stirring. Methylation of the sample was initiated by adding $0.5 \mathrm{ml}$ of dry $2 \mathrm{M}$ potassium dimethyl sulphinyl (dimsyl) anion prepared earlier by adding $4.8 \mathrm{~g}$ of potassium hydride (the Hakomori procedure uses $\mathrm{NaH}$ ) to $10 \mathrm{ml}$ of dry DMSO. Following the addition of the dim- syl anion, the reaction tube was flushed with nitrogen, capped, and stirred. After $8 \mathrm{~h}$ the sample tube was cooled in an ice bath until frozen, and $1.0 \mathrm{ml}$ of iodomethane was slowly added to complete the methylation. After stirring the sample overnight at room temperature, the reaction was quenched with $0.5 \mathrm{ml}$ of Milli- $Q$ and the methyl iodide was removed by evaporation under nitrogen (i.e. until the solution is clear and layerless). The methylated derivative was applied slowly to the top of a $\mathrm{C}-18$ reverse phase cartridge (Waters Sep-Pak) and washed with $8 \mathrm{ml}$ of Milli-Q water and eluted with 2 to $3 \mathrm{ml}$ of acetonitrile to remove DMSO. The dry, permethylated polysaccharide was hydrolyzed at $121^{\circ} \mathrm{C}$ for $2 \mathrm{~h}$ in $0.5 \mathrm{ml}$ of $2 \mathrm{M}$ TFA containing $20 \mu \mathrm{g}$ of myo-inositol. The reduction and acetylation of the generated monosaccharides were carried out as described above for alditol acetates, but substituting sodium borodeuteride for sodium borohydride in the reduction step. The partially methylated alditol acetates, finally dissolved in $100 \mu \mathrm{l}$ of methanol, were analyzed by GC-MS, using a VG-Autospec Mass Spectrometer equipped with a HP 5890 Gas Chromatograph. Samples were run on a Supelco, SP2330, $30 \mathrm{~m}$ fused silica column $10.25 \mathrm{~mm}$ ID, and $0.20 \mu \mathrm{m}$ film), using a temperature program of $80(2) / 30 / 170 / 4 / 240(10)$. Methylated monosaccharides were identified by comparing chromatographic and mass spectral properties with known standards.

Dissolved oxygen measurements. Samples for dissolved oxygen were collected in replicate. Fifty $\mathrm{ml}$ glass bottles were filled to the point of overflowing, capped with no head space and stored in the dark until analysis. Oxygen concentration measurements were made by Ms Amy Nolin at the Marine Biological Laboratory (Woods Hole, MA), using an automated Winkler titration system designed by Knapp et al. (1990).

\section{RESULTS}

\section{Phytoplankton cultures}

Over the $8 \mathrm{~d}$ of the experiment, chl $\mathrm{a}$ and POC values in the Thalassiosira weissflogii culture rose steadily to $1.8 \mathrm{mg} \mathrm{l}^{-1}$ and $6.8 \mathrm{mM}$, respectively, while total DOC values fluctuated (Fig. 2). DOC comprised 9\% of the total organic carbon (TOC) in the system on Day 8 , HMW DOC comprised $27 \%$ of DOC, and thus 2 to $3 \%$ of the TOC. Emiliania huxleyi grew slowly and at the time of harvesting (Day 22) the maximum POC value was $1.8 \mathrm{mM}$, while DOC comprised 9 to $10 \%$ of the TOC. Also at this time, HMW DOC was $25 \%$ of the total DOC or 2 to $3 \%$ of the TOC. For the Phaeocystis sp. culture, HMW DOC comprised $21 \%$ of the total DOC at the time of harvesting. 
Fig. 2 outlines the dynamics of the Thalassiosira weissflogii culture in more detail. Chl a $\left(\mathrm{mg} \mathrm{l}^{-1}\right)$ and POC ( $\mathrm{mM} \mathrm{C}$ ) increased steadily from inoculation to harvesting, reaching a POC/chl a ratio of 45 (Fig. 2A). In contrast, the changes in the carbon to nitrogen $(\mathrm{C} / \mathrm{N})$ ratio of the POC, shown in Fig. 2B, are more dynamic over this time period. Values rose from 4 to 6 during the first $2 \mathrm{~d}$ of the culture, remained approximately constant for the next $3 \mathrm{~d}$, and rose again sharply on Day 5 to a value of 10 , with little change thereafter. The final $\mathrm{C} / \mathrm{N}$ ratio of the POC was 10.6 (Day 8) corresponding to a PON concentration of $640 \mu \mathrm{M}$. This value agrees well with the $600 \mu \mathrm{M}$ loss of nitrate (1217 $\mu \mathrm{M}$ starting concentration ( $\mathrm{f} / 2$ concentrations) and $615 \mu \mathrm{M}$ on Day 8 ).

DOC concentrations in the culture also fluctuate, as shown in Fig. 2B. There was no measurable change in DOC concentration until Day 5 , when the value rose sharply by $560 \mu \mathrm{M}$ to a maximum concentration of $842 \mu \mathrm{M}$. This maximum was followed by a rapid decrease of $260 \mu \mathrm{M}$ to $582 \mu \mathrm{M}$ between Days 5 and 6 , and a slower, total increase of $53 \mu \mathrm{M}$, over the course of the next $3 \mathrm{~d}$ to Day 8 , at which time the culture was harvested (TW2 on Fig. 2).

The density of the bacterial population in the diatom culture, prior to harvesting, was monitored in order to determine the extent of the bacterial contribution to DOM. The amount of bacterial carbon was only a small percentage of the total DOC $(<1 \%)$ throughout the culture and a small percentage of the total HMW DOC $(<2 \%)$ present at the end of the culture. Coincident with the rapid decrease in DOC concentration from Day 5 to 6 , bacterial cell numbers also increase. Although the increase in cell numbers between Day 5 and 6 corresponds to a 3 -fold increase in the amount of bacterial carbon, this change accounts for only $3 \%$ of the loss in total DOC. If bacterial degradation alone was responsible for this DOC loss, nearly all (97\%) the DOC must have been respired as $\mathrm{CO}_{2}$ and not incorporated into the bacterial biomass. Bacterial growth yields are usually in the range of 10 to $20 \%$ (Kirchman et al. 1991, Smith et al. 1995). As the growth yields of $3 \%$ calculated above for our culture are unusually low, it is unlikely that bacteria are solely responsible for the loss of DOC. Other mechanisms, such as flocculation of DOC, must have played a role in the removal of DOC from our system. Bacteria were also present in the Emiliania huxleyi and Phaeocystis sp. cultures throughout the growth period, but accounted for less than $2 \%$ of the total DOC.

The ${ }^{1}$ HNMR data in Fig. 3 shows the HMW DOM present in the cultures at the time of harvesting, along with a spectrum typical for seawater (Coastal Research Laboratory, Woods Hole, MA; Fig. 3A). In all spectra, carbohydrate resonances dominate, with resonances
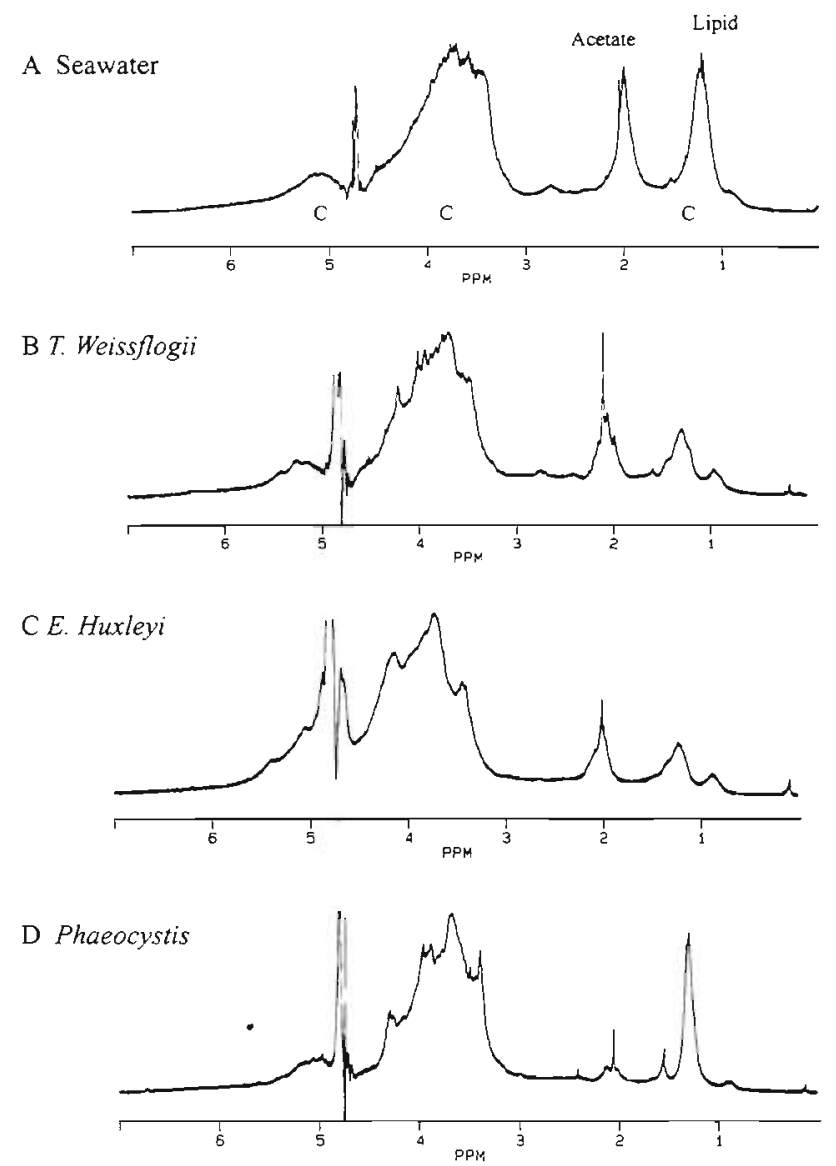

Fig. 3. ${ }^{1}$ HNMR spectra for HMW DOM isolated from (A) seawater (Woods Hole), and (B) the exudates of Thalassiosira weissflogii, (C) Emiliania huxleyi, and (D) Phaeocystis. Carbohydrate resonances are between 3.2 and $4.7 \mathrm{ppm}(\mathrm{CHOH})$, 5 and $5.8 \mathrm{ppm}$ (anomerics), and $1.3 \mathrm{ppm}\left(\mathrm{CH}_{3}\right.$ from deoxy sugars). Spectra also show proton resonances for acetate $(2.0 \mathrm{ppm})$ and lipids (1.3 and $0.9 \mathrm{ppm})$. The ratios of carbohydrate:acetate:lipid reported in the text are based on the areas under the peaks denoted $C$ (for carbohydrates), AC (for acetate) and Alkyl (lipids). To convert from hydrogen to carbon we use a $\mathrm{C} / \mathrm{H}$ ratio of 1 for carbohydrates, 0.67 for acetate and 0.5 for lipids

between 3.2 and $4.7 \mathrm{ppm}(\mathrm{C} \underline{\mathrm{HOH}}), 5$ and $5.8 \mathrm{ppm}$ (anomeric protons), and $1.3 \mathrm{ppm}\left(\mathrm{CH}_{3}\right.$, from rhamnose and fucose). Resonances at $2.0 \mathrm{ppm}\left(\mathrm{CH}_{3} \mathrm{COO}\right)$ arise from acetate and resonances at $0.9 \mathrm{ppm}\left(\mathrm{CH}_{3}\right)$, and other resonances at $1.3 \mathrm{ppm}\left(\mathrm{CH}_{2}\right)$ may arise from lipids. There is a close resemblance between the spectra of seawater and the exudates from Thalassiosira weissflogii and Emiliania huxleyi (Fig. 3B,C). Although both exudates show the presence of carbohydrates, acetate and lipids, the proportions of these constituents differ somewhat from seawater. The ratio of carbohydrates:acetate:lipid carbon, calculated using ${ }^{1} \mathrm{HNMR}$ peak areas, is 91:6:3 for the $T$. weissflogii exudate, and 91:7:2 for the E. huxleyi exudate. For comparison, this 


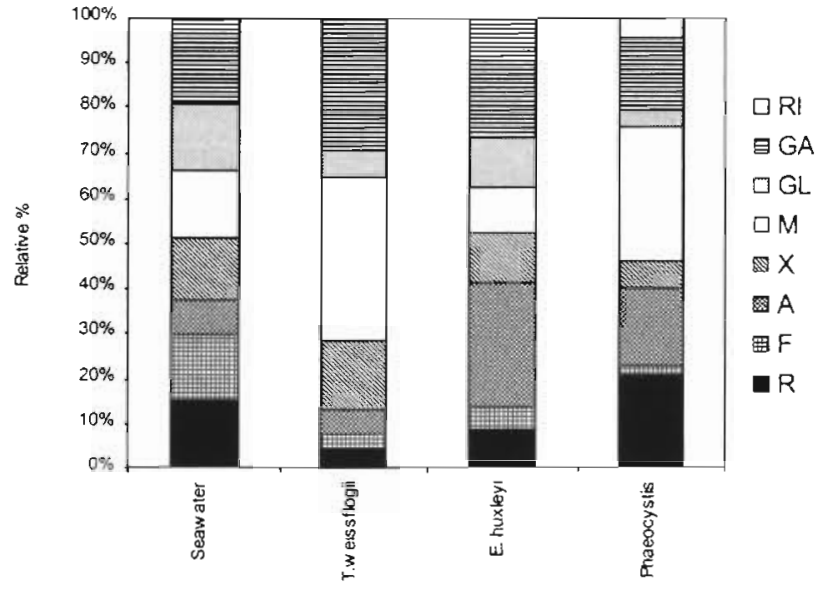

Fig. 4. The relative distribution of monosaccharides in HMW DOM isolated from seawater, and the exudates of Thalassiosira weissflogii, Emiliania huxleyi, and Phaeocystis sp. R: rhamnose, $F$ : fucose, A: arabinose, $X$ : xylose, $M$ : mannose, GL: glucose, GA: galactose, RI: ribose. The seawater sample represents the average distribution of monosaccharides in 10 seawater samples (the standard deviation is less than $\pm 3 \%$ for each monosaccharide

ratio in seawater HMW DOM is $80: 10: 10$. The NMR spectrum of the Phaeocystis sp. exudate is quite different (Fig. 3D) from the other exudates. As in the other spectra, the carbohydrate peak is dominant with resonances between 3.2 and $4.7 \mathrm{ppm}$. However, the acetate peak at $2.0 \mathrm{ppm}$ is much smaller and the peak at $1.3 \mathrm{ppm}$, derived primarily from deoxy sugars in this case, is more pronounced. Other peaks between 0.9 and $1.5 \mathrm{ppm}$, attributed to lipids, are also present in this sample, but in relatively smaller concentrations. The ratio of carbohydrate:acetate:lipid carbon in this sample is $95: 1.5: 1.5$, again showing the relative excess of carbohydrates compared to seawater. For all spectra (including seawater), the carbohydrate, acetate and lipid resonances discussed above account for approximately 70 to $75 \%$ of the total carbon in each sample.
The relative distribution of neutral monosaccharides in the HMW fraction of each of the 3 exudates and seawater, analyzed as alditol acetates, are shown in Fig. 4. In all cases, including seawater HMW DOM samples, alditol acetate analyses underestimate the yield of carbohydrates determined by ${ }^{1} \mathrm{HNMR}$ by approximately $50 \%$. The seawater sample shown in Fig 4 is the average monosaccharide distribution in 10 APS samples from the Northwest Atlantic, an estuary in Oosterschelde (Aluwihare et al. 1997), the Sargasso Sea and the Gulf of Mexico (McCarthy et al. 1996), and Mikawa Bay (Sakugawa \& Handa 1985). This distribution shows equal proportions of rhamnose, fucose, xylose, mannose and glucose $(14 \pm 1 \%)$ with galactose being slightly enriched $(21 \%)$ and arabinose being slightly depleted $(6 \%)$ (Fig. 4). While the exudates shown in Fig. 4 also contain the same 7 neutral monosaccharides, the relative proportions of these monosaccharides differ substantially for each sample. The relative distribution of monosaccharides in the Thalassiosira weissflogii exudate shows $4.3 \pm 1 \%$ each of rhamnose, fucose, arabinose and glucose, $15 \%$ xylose, $37 \%$ mannose and $30 \%$ galactose. In the case of Emiliania huxleyi, the proportions are $5 \%$ fucose, $9 \pm 1 \%$ each of rhamnose, mannose and glucose, $12 \%$ xylose, $30 \%$ arabinose, and $24 \%$ galactose. The major monosaccharides in the Phaeocystis sp. exudate are mannose (30\%), rhamnose $(21 \%)$, arabinose $(17 \%)$ and galactose $(16 \%)$. Xylose, glucose and fucose are also present, but in smaller quantities $(6,4$ and $2 \%$, respectively). This exudate also contains an additional neutral monosaccharide, ribose, in a small quantity. The abundance of rhamnose, a deoxy sugar, is clearly seen as a pronounced resonance at $1.3 \mathrm{ppm}$ in the ${ }^{1} \mathrm{HNMR}$ spectrum of this exudate.

While in review, 1 referee noted that results from a similar study on monosaccharide distributions in the HMW exudates of phytoplankton was due to appear shortly in the journal Marine Chemistry (Biersmith \& Benner 1998). We refer the reader to this paper for further information on this topic.
Table 1. Ancillary data for the HMW DOM isolated from the phytoplankton cultures. Day 0, in all cases (Thalassiosira weissflogii [TW2, TW3, TW4, TW5 and TW6], Emiliana huxleyi and Phaeocystis sp.), marks the beginning of the phytoplankton cultures. TM is the yield of total hydrolyzable neutral monosaccharides

\begin{tabular}{|lrrcrrr|}
\hline Sample & $\begin{array}{c}\text { Time } \\
(\text { day })\end{array}$ & $\begin{array}{c}\text { [DOC }] \\
(\mu \mathrm{M})\end{array}$ & $\begin{array}{c}\text { HMWDOC } \\
(\mu \mathrm{M})\end{array}$ & $\% \mathrm{HMW}$ & $\begin{array}{c}\text { TM } \\
(\mu \mathrm{M})\end{array}$ & $\begin{array}{c}\mathrm{C} / \mathrm{N} \\
(\mathrm{HMW})\end{array}$ \\
\hline TW2 & 9 & 632 & 171 & 27 & 48 & 14.0 \\
TW3 & 17 & 484 & 179 & 37 & 39 & 10 \\
TW4 & 31 & 320 & 63 & 20 & 10 & 7.2 \\
TW5 & 61 & 269 & 58 & 21 & 3 & 5.6 \\
TW6 & 218 & 161 & 12 & 7 & 1 & 8.85 \\
E. huxleyi & 22 & 194 & 49 & 25 & 17 & 9.6 \\
Phaeocystis sp. & 10 & 520 & 111 & 21 & 54 & 12.0 \\
\hline
\end{tabular}

\section{Bacterial degradation of the Thalassiosira weissflogii exudate}

In order to observe chemical changes in the exuded DOM due to bacterial degradation, the algae were harvested by filtering on Day 8 and the filtrate inoculated with Whatman GF/F filtered seawater. The changes in total DOC after inoculation are also shown in Fig. 2B (Days 9 to 218) and given in Table 1. 
Three hundred $\mu \mathrm{MC}$ were lost from the DOC pool during the first $3 \mathrm{wk}$ (Days 9 to 31 ) of the incubation experiment. Approximately $50 \%$ of this DOC removal occurred over the first week of the incubation (Day 9 through 17, TW2 to TW3 from Fig. 2, and Table 1), during which time the concentration of HMW DOC showed no change. Over this time period there must. have been a balance between the production and removal of DOC within the HMW fraction (note changes in the ${ }^{1} \mathrm{HNMR}$ data [Fig. 5], HMW monosaccharide data [TM in Table 1] and C/N ratios in the HMW fraction between these 2 time points). Thus the net change in DOC concentration reflects the reactivity of the $\angle 1 \mathrm{kD}$ (low molecular weight) fraction of DOC during the first week of the degradation, and suggests some synthesis of HMW DOM from LMW DOM by microbes. During the next 2 wk (Days 17 to 31; TW3 to TW4 from Fig. 2 and Table 1) the concentration of HMW DOC decreased by $100 \mu \mathrm{M}$ accounting for $70 \%$ of the loss in total DOC. After the first $3 \mathrm{wk}$, the removal of DOC slows down considerably. From Day 31 to 61 (TW4 to TW5, Fig. 2 and Table 1), the $50 \mu \mathrm{M}$ decrease in total DOC concentration is accompanied by little change in the concentration of HMW DOC. Removal rates continue to decrease over the last $5 \mathrm{mo}$ of the experiment (TW5 to TW6), resulting in a $100 \mu \mathrm{M}$ decrease in the total DOC concentration. The concentration of HMW DOC also decreases over this time period, and can account for approximately $30 \%$ of the loss from the total DOC pool.

${ }^{1}$ HNMR spectrometry was used to monitor the changes in HMW DOM as the total Thalassiosira weissflogii exudate was degraded. Shown in Fig. 5 are spectra for the HMW exudate 1 wk (5A, Day 17, TW3) and 3 wk (5B, Day 31, TW4) after the inoculation. The NMR spectra of TW5 and TW6 are very similar to the NMR spectra of TW3 and TW4, with only small differences in the areas of the peaks between 1.9 and $3.1 \mathrm{ppm}$. When these spectra are compared to the ${ }^{1}$ HNMR spectrum of the $T$. weissflogii exudate at the time of harvesting (Day 9 of the experiment) shown in Fig. 3B, new resonances in the region between 1.9 and $3.1 \mathrm{ppm}$ are apparent. These resonances may be attributed to proteins excreted into the medium by microorganisms, or to small microbes $(<0.2 \mu \mathrm{m})$ concentrated in the sample during ultrafiltration. Protein resonances were removed by passage through a cation exchange column (BioRad AG 50W-X8), which increases the C/N ratios of the samples from 10 and 7 (prior to passage through the column) to 14 (after passage through the cation exchange column), consistent with removal of protein (nitrogen containing fraction). The ${ }^{1} \mathrm{HNMR}$ spectra of these cleaned samples (Fig. 5 inset) closely resemble the spectrum of HMW DOM isolated when the algae were harvested (Fig. 3B) and the seawater spectrum shown in Fig. 3A.
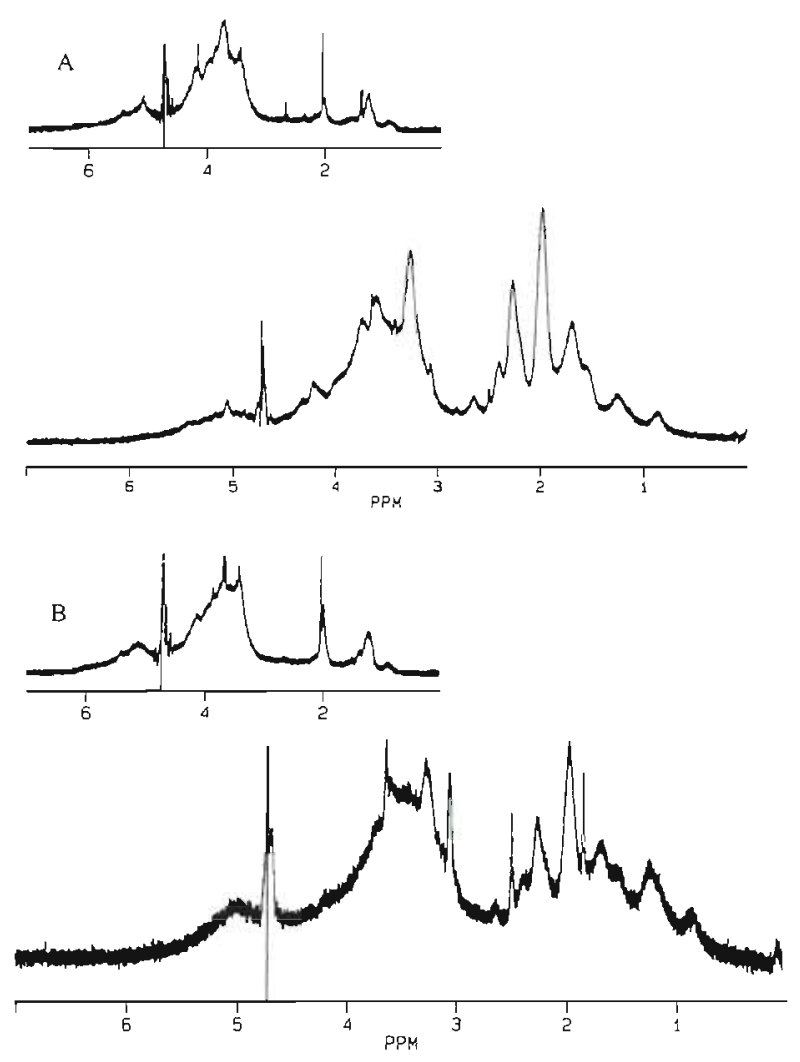

Fig. 5. 'HNMR spectra of 2 HMW DOM samples isolated during the degradation of the Thalassiosira weissflogii exudate, (A) TW3 and (B) TW4. Resonances between 1.9 and $3.1 \mathrm{ppm}$ are thought to arise from proteins which can be removed by passage through a cation exchange column (insets)

The removal of polysaccharides during the incubation of the Thalassiosira weissflogii exudate was followed by changes in the relative distribution of monosaccharides in HMW DOM. The overall changes occur in 3 stages. During the first stage which spans the first 3 weeks of the incubation (TW2 [Day 9] to TW4 [Day 31]], polysaccharide concentrations (as measured by alditol acetates) decrease by $80 \%$; this accounts for $40 \%$ of the decrease in the HMW DOC concentration. Mannose and galactose are preferentially removed, compared to other monosaccharides, with an overall $90 \%$ decrease in mannose concentration, and a $75 \%$ decrease in galactose concentration. At the end of the third week, galactose, mannose and xylose are still the most abundant sugars but their dominance is diminished, making the relative distribution of sugars more even. Between TW4 (Day 31) and TW5 (Day 61), there is a decrease in the concentrations of all monosaccharides (except arabinose). Rhamnose, xylose, mannose and galactose all experience an 80 to $90 \%$ decrease in concentration, indicating preferential removal of these sugars (compared to other components in HMW DOC) 
during the second month of the degradation. The relative distribution of monosaccharides also changes over the last 5 mo (TW5 to TW6) of the degradation caused by an increase in glucose and fucose concentrations, and a decrease in arabinose concentration.

At Day 218 of the experiment, when DOC concentrations had reached $161 \mu \mathrm{M}$, the filtrate was re-inoculated to determine if any microbially labile DOC remained in the culture. Following the inoculation, oxygen concentration measurements yielded a total consumption of $7 \mu \mathrm{M}$ oxygen over a $3 \mathrm{mo}$ period, indicating that the remaining organic matter was refractory to bacterial degradation (nutrient concentrations remained high throughout this period).

\section{DISCUSSION}

\section{Phytoplankton cultures}

The major goals of this study were to determine if HMW polysaccharides produced by algae chemically resemble acyl polysaccharides (APS) isolated from seawater and to monitor changes in the chemical characteristics of the exuded polysaccharides during microbial degradation. As shown by ${ }^{1} \mathrm{HNMR}$, seawater APS consist mainly of carbohydrates $(80 \pm 4 \%$ of the total carbon), acetate (10 $\pm 2 \% \mathrm{C})$ and lipid $(9 \pm 4 \% \mathrm{C})$. Monosaccharide analyses have shown that APS are composed of 7 major neutral monosaccharides, rhamnose, fucose, xylose, arabinose, mannose, glucose and galactose present in a relatively fixed ratio (Aluwihare et al. 1997).

${ }^{1}$ HNMR spectra shown in Fig. 3 indicate that the HMW DOM produced by Thalassiosira weissflogii and Emiliania huxleyi have spectral characteristics similar to seawater APS. However, the relative areas of these spectra indicate an excess of carbohydrate in extracellular HMW DOM isolates compared to seawater. In the case of Phaeocystis sp., the 'HNMR spectrum shows very little acetate (ratio of $95: 1.5: 1.5$, for carbohydrate: acetate:lipid carbon).

When the distribution of monosaccharides in each of the exudates (Fig. 4) is compared to seawater, the presence of polysaccharides other than APS, is apparent. The differences between the ${ }^{1}$ HNMR spectra of seawater and algal exudates further reflect differences in the carbohydrate composition of these samples (between 3.5 and $4.5 \mathrm{ppm}$ ). Unlike seawater, where the major polysaccharide is APS, the algal exudates are comprised of a mixture of polysaccharides, including APS. The abundance of polysaccharides in the exudates relative to seawater HMW DOM is indicated by the yield of monosaccharides upon hydrolysis (Table 1). In surface seawater, neutral monosaccharides, analyzed as alditol acetates, contribute between 7 and $20 \%$ of the carbon in HMW DOM (McCarthy et al, 1996, Borch \& Kirchman 1997, Skoog \& Benner 1997, Aluwihare \& Repeta unpubl.). At the time of harvesting, neutral monosaccharides were $28 \%$ of the total HMW DOC in the Thalassiosira weissflogii exudate, $35 \pm 10 \%$ of the Emiliania huxleyi exudate, and $49 \pm 9 \%$ of the Phaeocystis sp. exudate.

In order to investigate the similarity between seawater APS and the algal exudates, we calculated the correlation between the relative distribution of monosaccharides in each culture sample and seawater. The correlation coefficient between samples is calculated by dividing the covariance in the monosaccharide distribution of 2 samples (e.g. seawater vs Thalassiosira weissflogii) by the product of their standard deviations $(\sigma)$. In all cases, the absolute values of the correlation coefficients are reported. The $T$. weissflogii sample (at the time of harvesting) exhibits only a weak correlation with seawater $(0.34)$, confirming that the monosaccharide distribution in these 2 samples is quite different. Two correlation coefficients were calculated for Emiliania huxleyi. The first (0.32) was generated using the monosaccharide distribution shown in Fig. 4 , while the second $(0.85)$ was generated after arabinose (the dominant sugar in the distribution) was removed from the analysis. Without arabinose (which contributes $30 \%$ of the monosaccharides in HMW DOM), the monosaccharide distribution in the exudate closely resembles the distribution seen for seawater. This analysis is consistent with the conclusion that the HMW exudate from E. huxleyi is comprised mainly of APS and an arabinose dominated polymer. For Phaeocystis sp., the sugar distribution cannot be easily manipulated to increase the correlation coefficient $(0.28)$ because several of the monosaccharides dominate the exudate (see Fig. 4).

While the ${ }^{1}$ HNMR data support the idea that the Thalassiosira weissflogii and Emiliania huxleyi exudates contain APS, the monosaccharide and correlation coefficient analyses imply that if APS is present, it is only a fraction of the total polysaccharides in each exudate. In the case of Phaeocystis sp., the relative distribution of monosaccharides together with the NMR data suggests that APS is at most only a very small component of the total HMW exudate

Non APS monosaccharides in each exudate were estimated by assuming that all the rhamnose present is from APS, and scaling the neutral monosaccharides to rhamnose according to their relative distribution in seawater APS. The excess monosaccharides in the Thalassiosira weissflogii exudate are mannose and galactose $(\sim 40 \%$ each of the total excess) and to a lesser extent, glucose $(12 \%)$ and xylose $(8 \%)$. In the case of Emiliania huxleyi, the relative distribution is 
close to that of seawater (as indicated by the correlation analyses), with the major excess being arabinose (50\% of the total excess), and galactose $(35 \%)$. The excess in the neutral hexoses can be explained by the presence of storage polysaccharides in the exudates. The excess over APS in these 2 cultures reside in 2 or 3 sugars, indicating that the polymers other than APS are likely to be quite simple compared with the heterogeneity of APS

Results from the linkage analysis for rhamnose, fucose, xylose, glucose and galactose in the total HMW DOM isolated from seawater and the cultures at the time of harvesting are shown in Fig. 6 as TW2, Emiliania huxleyi, and Phaeocystis sp. Individual polysaccharides are made up of monosaccharide monomers bonded together in specific molecular configurations. Information on the bonding or linkage sites can be obtained by methylating the free (non-linked) hydroxyl groups within the polysaccharide, hydrolyzing the polysaccharide (i.e. breaking the linkages) and labeling the linkage sites with acetate. Most of the linkages present in seawater are found in the culture samples, and in all cases, their relative abundance in the culture samples fall within the range observed for seawater. From this data it is apparent that the exudates from Thalassiosira weissflogii and $E$. huxleyi could contain compounds related to APS. The Phaeocystis sp. sample shows some significant differences compared to the other 2 samples and compared to seawater. With the exception of rhamnose (the second most abundant sugar), this sample has fewer linkages per sugar, for example, $50 \%$ of arabinose present is linked at all positions (i.e. $1,2,3,4) ; 40 \%$ of rhamnose is terminal and $69 \%$ of xylose is linked at carbon 1,2 , and 3 . Fucose was only identified linked at all positions; however, this is the least abundant sugar in the sample, and other linkages may be present in very small quantities. The simplicity of the Phaeocystis sp. linkage data suggests that this exudate probably contains a much simpler mixture of polysaccharides compared with the other 2 exudates, and is perhaps dominated by 1 major class of related polysaccharides.

The presence of polysaccharides in the exudates of diatoms grown in culture, has been noted in numerous studies (Allan et al. 1972, Hecky et al. 1973, Myklestad 1974, Smestad et al. 1975, Haug \& Myklestad 1976, Percival et al. 1980). All the species examined produced extracellular DOM with varying amounts of
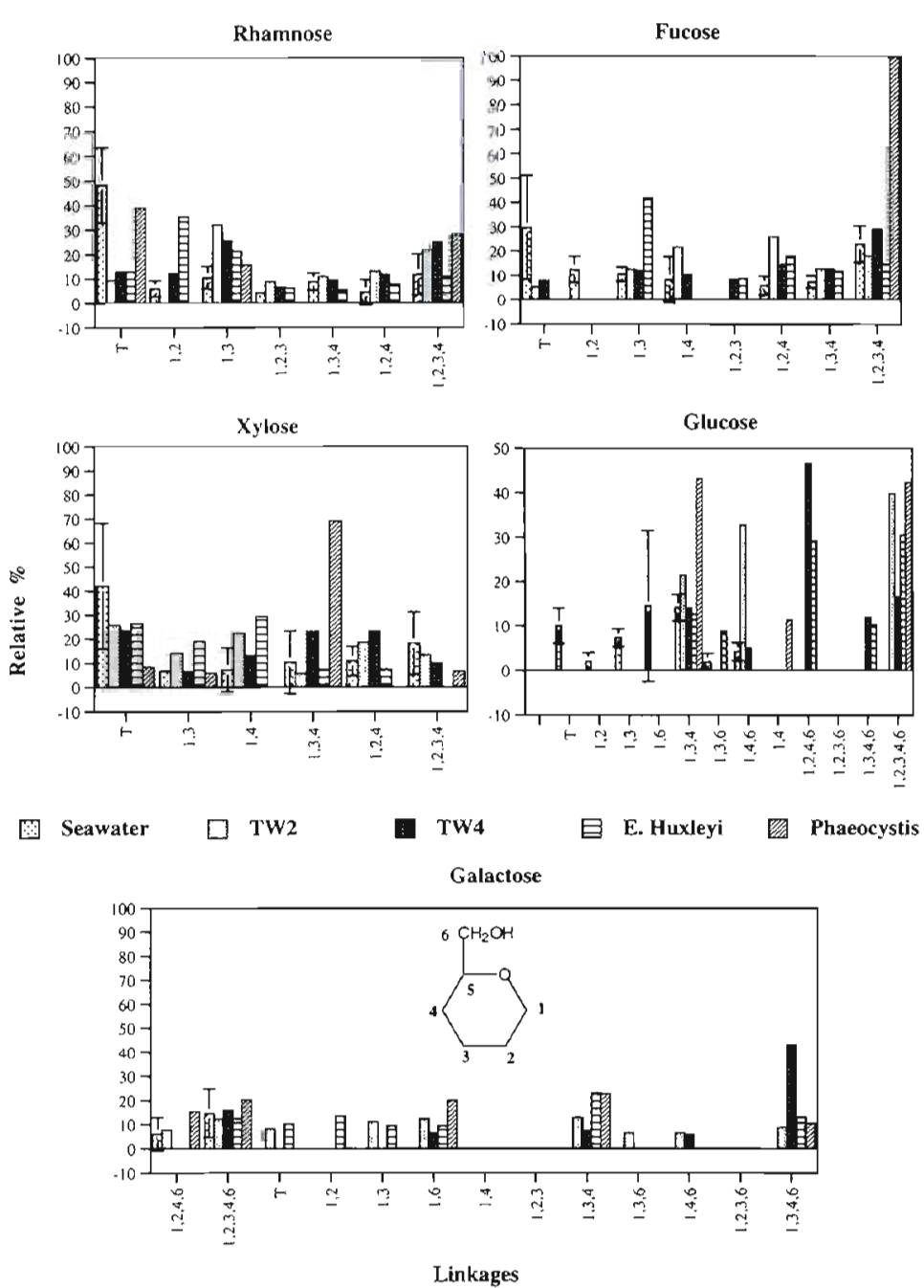

Fig. 6. Carbohydrate linkage data for the exudates. TW2, Emiliana huxleyi and Phaeocystis sp. samples were taken when the cultures were harvested. TW4 was isolated during the Thalassiosira weissflogii incubation experiment. The number beneath each bar refers to the linkage site on each monosaccharide (i.e. carbon 1 and 6 as 1,6), and $T$ refers to linkages through carbon 1 only. Only linkages which constitute $>5 \%$ of each sugar are listed

rhamnose and galactose. When fucose was present it was a major fraction of the total monosaccharides, while xylose, arabinose, mannose, and glucose were found in varying amounts in most of the exudates. The above data demonstrate the heterosaccharide nature of the exuded polymers in accordance with what is observed in this study. In contrast, the extraction of whole diatom cells with water mainly yields homopolymers such as glucans. However, cell walls and the alkali soluble fraction of whole cells have also been shown to contain many of the different monosaccharides discussed above. Direct comparison of the relative distribution of these monosaccharides indicate that for the diatoms considered in these studies (Allan et al. 1972, 
Myklestad et al. 1972), clear compositional differences exist between intracellular and extracellular carbohydrates. Some chemical data are also available on extracellular DOM produced by Phaeocystis sp. The organic mucus which surrounds the cell has been shown to be polysaccharide (Painter 1983), but the monosaccharide composition of this gel-like material seems to vary among species. Janse et al. (1996) reported the presence of arabinose, xylose, mannose, galactose, glucose, rhamnose, glucouronate and small quantities of O-methylated sugars in the large extracellular gels isolated from surface waters in the North Sea. Guillard \& Hellebust (1971) found that the DOM exuded by isolates from Vineyard Sound, MA, and Surinam was composed of mannose, rhamnose, glucose, ribose, arabinose, galactose, xylose, and uronic acids in varying amounts. The Phaeocystis sp. grown in this study (CCMP 628) was an isolate from coastal Surinam and contained the complex mixture of neutral monosaccharides (including ribose) observed by other investigators. In our samples the dominant sugars are arabinose, rhamnose, and mannose, with fucose present only in a very small amount. Fucose has not been reported in the literature to be abundant in Phaeocystis extracellular polysaccharides. While the monosaccharide distributions discussed above are qualitatively similar to the HMW polysaccharides isolated from seawater, these distributions alone do not allow a definitive comparison between the polymers isolated from seawater and those exuded by phytoplankton in culture.

\section{Degradation of the Thalassiosira weissflogii exudate}

Norman et al. (1995) demonstrated the algal production of DOM with a range of reactivities. Here, we expand on their study by following the compositional changes within the polysaccharide fraction, including APS, as the total Thalassiosira weissflogii exudate was subjected to microbial degradation. These data can be used to determine if the chemical composition of the refractory material persisting in culture differs from the chemical composition of the compounds present at the time of exudation. In addition, we directly compare the DOM present at the end of the degradation to the DOM isolated from seawater.

To quantitatively compare HMW DOM left in the degradation experiment (Fig. 5 insets) with APS isolated from seawater (Fig. 3A), we used the carbohydrate to acetate carbon ratio in each of these samples. This ratio varies little in seawater APS $(8 \pm 2)$, and is well established by our previous studies (Aluwihare et al. 1997). Although both inset spectra in Fig. 5 contain the same resonances, there is a difference in the rela- tive abundance of acetate. The carbohydrate:acetate carbon ratio at the time of harvesting (Fig. 3B) is 15, and at TW3, after $1 \mathrm{wk}$ of degradation (Fig. 5A inset), is comparable at 18 . Two weeks later, at TW4, (Fig. 5B inset) the ratio drops to 10 , not significantly different from the ratio of $8( \pm 2)$ observed for seawater. One month later, at TW 5, this ratio is still 10. However, at TW6 (5 mo later), the ratio is closer to 13 and this is consistent with the changes in the monosaccharide data discussed below. The overall decrease in this ratio is brought about by a more rapid loss of total carbohydrate compared to the acetate containing (perhaps APS) fraction. This indicates that the different polysaccharides within the exudate have different removal rates, consistent with the findings of Norrman et al. (1995), and as the exudate is degraded, the remaining polysaccharide component resembles APS more closely. Collectively, the NMR data indicate that a component closely resembling seawater APS is produced by Thalassiosira weissflogii in culture (Fig. $3 \mathrm{~B}$ ) and is present throughout the incubation (Fig. 5A,B). Furthermore, carbohydrate: acetate carbon ratios indicate that this APS component is concentrated relative to other HMW components as the degradation proceeds.

The neutral monosaccharide data, for the different time points during the incubation, support the relative persistence of APS as HMW DOM is degraded. During the degradation there is a shift in the monosaccharide distribution from one that is dominated by the hexoses (mannose and galactose) to one that is more evenly distributed amongst the 7 neutral sugars. Consistent with the NMR data, the monosaccharide data indicate that a polysaccharide resembling APS exists within the algal exudate, but that its presence is partially obscured by the presence of other hexose dominated polysaccharides. For example, the degradation pattern of mannose is unique and can be modeled using a first order exponential function $\left(\mathrm{r}^{2}=0.9\right)$, indicating that most of the mannose is likely present within a polysaccharide that is degraded quickly.

The shift in the relative proportions of each monosaccharide towards a seawater like distribution can be demonstrated using correlation coefficient analysis. This analysis determines how well the distribution of monosaccharides at each time point during the incubation correlates with the distribution observed for average seawater. TW2 and TW3 are closely correlated with each other $(0.9)$ but only exhibit a small correlation with seawater $(0.32$ and 0.33 , respectively). TW4 and TW5 exhibit stronger correlations with seawater, 0.7 and 0.8 , respectively, showing that as the exudate is degraded, the monosaccharide distribution in the HMW exudate approaches the distribution observed for seawater. At the end of the incubation (TW6), the correlation coefficient is lower than at the beginning of 
the experiment $(0.15)$, due to a relative increase in glucose and fucose. These sugars may be preferentially concentrated with time and/or added during the incubation. The low correlation at TW6 is consistent with the increase in the carbohydrate:acetate ratio calculated from the NMR spectrum, indicating a change in the relative abundance of APS between TW5 and TW6. As shown by the correlation coefficient analysis, there is a considerable change in the relative distribution of monosaccharides over the course of the incubation. Given these changes in the monosaccharide distribution, we were interested to see if the linkage data showed similar variations. The linkage data from 2 time points, TW2 and TW4, are compared in Fig. 6. The linkage pattern of each monosaccharide falls within the range observed for seawater. In some cases, (for example the deoxy hexoses and pentoses), the linkage pattern in TW4 more closely approaches the average seawater distribution, consistent with the correlation coefficient analysis. However, the variation in the linkage patterns between these 2 time points is not reflective of the much more pronounced difference in their relative monosaccharide distribution. Before any specific conclusions can be drawn from these results, however, more data and analyses are necessary.

An accumulation of the APS-like component relative to other polysaccharides in the incubation experiment is suggested by the changes in the carbohydrate: acetate carbon ratio calculated from the ${ }^{1} \mathrm{HNMR}$ spectra and the relative distribution of monosaccharides. Given these data, we attempt to compare the change in the concentration of total polysaccharides (as analyzed by alditol acetates) to the change in the relative concentration of the component resembling APS over the course of the degradation (Fig. 7). The APS fraction is calculated by assuming that all the rhamnose in HMW DOM is present within APS at each of the time points sampled during the degradation. Total APS concentrations are calculated using the seawater monosaccharide distribution shown in Fig. 4. We normalize our monosaccharide data to rhamnose because it is the least abundant monosaccharide at the beginning of the incubation and thus estimates the maximum possible loss of APS over the course of the incubation. Both APS and total polysaccharide concentrations decrease over the course of the incubation, however, the initial rate of degradation is slower for the calculated APS fraction than for the total polysaccharides. Thus, the percentage of APS in the total polysaccharide fraction increases from 31 to $78 \%$ over the course of the incubation. This data suggests that although APS is labile, there are other polysaccharides within the exudate that are degraded faster than APS.

In a recent study, Carlson et al. (1998) investigated the quality of DOM available to bacteria in the Ross

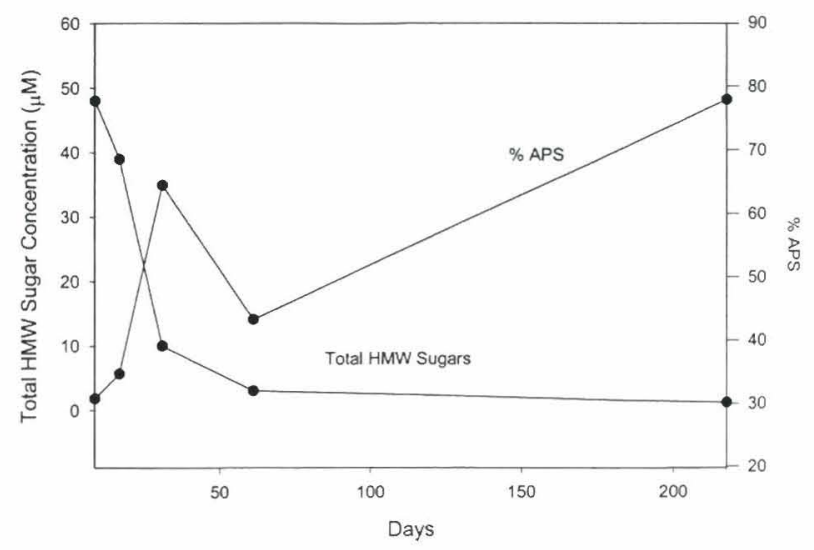

Fig. 7. The change in the concentration of total neutral monosaccharides in HMW DOM and the change in APS as a percentage of the total neutral monosaccharides (as calculated in the text) over the course of the Thalassiosira weissflogii incubation experiment

Sea polynya and the Sargasso Sea. The bloom in the Ross Sea was dominated by an Antarctic Phaeocystis species, while the Sargasso Sea bloom was dominated by picoplankton (with some haptophytes and diatoms also present). A comparison between the 2 sites showed that the DOM produced in the Ross Sea was readily available to bacteria, while approximately $50 \%$ of the new DOM produced in the Sargasso Sea escaped microbial degradation, suggesting an inherent difference in the DOM produced at these locations. This study supports our findings on the interspecies (Phaeocystis sp. vs Thalassiosira weissflogii and Emiliania huxleyi) differences we observe in the chemical composition of HMW DOM exudates, and the differences in the relative lability of dissolved organic compounds produced during algal photosynthesis.

Many factors can control the rates of degradation of individual heteropolymers by bacteria. First, these molecules must be hydrolyzed extracellularly, and, second, the bacteria must be able to produce enzymes that recognize the individual bonds within the polymer. It has been speculated that structural polysaccharides are synthesized to be particularly resistant to bacterial degradation (Thingstad \& Billen 1994). For example, investigators have noted the heterogeneity in the distribution of monosaccharides in diatom cell walls (Allan et al. 1972, Myklestad et al. 1972), and this heterogeneity may impart a resistance to bacterial degradation. Both the culture exudates and seawater APS exhibit complex monosaccharide distributions. The complex distribution of monosaccharides in APS, and its slower degradation relative to other polysaccharides in our experiment suggests that the persistence of APS in seawater may be due to its inherent resistance to bacterial degradation. 
In summary, polysaccharides with a chemical composition very similar to APS in seawater are produced by some phytoplankton during growth. APS may comprise up to $2-3 \%$ of TOC, $7 \%$ of the POC, and $30 \%$ of the HMW DOC at the time of production. Even though all polysaccharides within the exudate are removed during bacterial degradation, the APS in our experiment appear to be more resistant to microbial degradation than other polysaccharides.

Acknowledgements. This work was supported by a grant from the Department of Energy (DE-FG02-92ER61428). This is WHOI contribution 10004

\section{LITERATURE CITED}

Allan G, Lewin J, Johnson PG (1972) Marine polymers IV diatom polysaccharides. Bot Mar 15:102-108

Alldredge AL, Passow U, Logan BE (1993) The abundance and significance of a class of large, transparent organic particles in the ocean. Deep-Sea Res I 40:1131-1140

Aluwihare LI, Repeta DJ, Chen RF (1997) A major biopolymeric component to dissolved organic carbon in surface sea water. Nature 387:166-169

Baines SB, Pace ML (1991) The production of dissolved organic matter by phytoplankton and its importance to bacteria: patterns across marine and freshwater systems. Limnol Oceanogr 36(6):1078-1090

Biersmith A, Benner R (1998) Carbohydrates in phytoplankton and freshly-produced dissolved organic matter. Mar Chem 63:131-144

Borch NH, Kirchman DL (1997) Concentration and composition of dissolved combined neutral sugars (polysaccharides) in seawater determined by HPLC-PAD. Mar Chem 57:85-95

Carlson CA, Ducklow HW (1995) Dissolved organic carbon in the upper ocean of the central equatorial Pacific Ocean, 1992: daily and finescale vertical variations. Deep-Sea Res 42(2-3):639-650

Carlson CA, Ducklow HW, Hansell DA, Smith WO Jr (1998) Organic carbon partitioning during the spring phytoplankton blooms in the Ross Sea polynya and the Sargasso Sea. Limnol Oceanogr 43(3):375-386

Fogg GE (1962) Extracellular products. In: Lewin RA (ed) Physiology and biochemistry of algae. Academic Press, New York, p 475-489

Fogg GE (1966) The extracellular products of algae. Oceanogr Mar Biol Annu Rev 4:195-212

Fogg GE (1971) Extracellular products of algae in fresh water. Arch Hydrobiol 5:1-25

Fuhrman J (1992) Bacterioplankton roles in the cycling of organic matter: the microbial food web. In: Falkowski PG, Woodhead AD (eds) Primary productivity and biogeochemical cycles in the sea. Plenum Press, New York, p 361-383

Guillard RRL, Hellebust JA (1971) Growth and the production of extracellular substances by two strains of Phaeocystis pouchetii. J Phycol 7:330-338

Guillard RRL, Ryther JH (1962) Studies on marine planktonic diatoms I, Cyclotella nana Hustedt and Detonula confervacae (Cleve). Gran Can J Microbiol 8:229-239

Hakomori SI (1964) A rapid permethylation of glycolipid, and polysaccharide catalyzed by methylsulfinyl carbanion in dimethyl sulfoxide. J Biochem 55(2):205-208
Haug A, Mykelstad S (1976) Polysaccharides of marine diatoms with special reference to Chaetoceros species. Mar Biol 34:217-222

Hecky RE, Mopper K, Kilham P, Degens ET (1973) The amino acid and sugar compositions of diatom cell walls. Mar Biol 19:323-331

Hedges JI (1991) Marine particles: analysis and characterization: lignin, cutin, amino acid and carbohydrate analyses of marine particulate organic matter. Geophys Monogr 63:129-137

Hellebust JA (1965) Excretion of some organic compounds by marine phytoplankton. Limnol Oceanogr 10:192-206

Hobbie JE, Daley RJ, Jasper S (1977) Use of Nuclepore filters for counting bacteria by fluorescence microscopy. Appl Environ Microbiol 33(5):1225-1228

Janse I, van Rissel M, Gottschal JC, Lancelot C, Gieskes WWC (1996) Carbohydrates in the North Sea during spring blooms of Phaeocystis: a specific fingerprint. Aquat Microb Ecol 10:97-103

Jensen LM (1983) Phytoplankton release of extracellular organic carbon, molecular weight, composition, and bacterial assimilation. Mar Ecol Prog Ser 11:39-48

Keller MD, Selvin RC, Claus W, Guillard RRL (1987) Media for the culture of oceanic ultraphytoplankton. J Phycol 23 $663-638$

Knapp GP, Stalcup MC, Stanley RJ (1990) Automated oxygen titration and salinity determination. Woods Hole Oceanographic Institution Technical Report WHOI-90-35, Woods Hole, MA

Lampert W (1978) Release of dissolved organic carbon by grazing phytoplankton. Limnol Oceanogr 23:831-834

Lee S, Fuhrman JA (1987) Relationships between biovolume and biomass of naturally-derived marine bacterioplankton. Appl Environ Microbiol 52:1298-1303

Mague TH, Friberg E, Hughes DJ, Morris I (1980) Extracellular release of carbon by marine phytoplankton a physiological approach. Limnol Oceanogr 25(2):262-279

McCarthy M, Hedges JI, Benner R (1996) Major biochemical composition of dissolved high moleculare weight organic matter in seawater. Mar Chem 55:282-297

Myklestad S (1974) Production of carbohydrates by marine planktonic diatoms. I. Comparison of nine different species in culture. J Exp Mar Biol Ecol 15:261-274

Myklestad S, Haug A, Larsen B (1972) Production of carbohydrates by the marine diatom Chaetoceros affinis var. Willei (Gran) Hustedt. II. Preliminary investigation of the extracellular polysaccharide. J Exp Mar Biol Ecol 9:137-144

Nagata T, Kirchman DL (1992) Release of macromolecular organic complexes by heterotrophic marine flagellates. Mar Ecol Prog Ser 83:233-240

Norrman B, Zwiefel U, Hopkinson CS, Fry B (1995) Production and utilization of dissolved organic carbon during an experimental diatom bloom. Limnol Oceanogr 40(5): 898-907

Painter TJ (1983) Algal polysaccharides. In: Aspinol GO (ed) The polysaccharides, Vol 2. Academic Press, New York, p 195-285

Peltzer ET, Brewer PG(1993) Some practical aspects of measuring DOC - sampling artifacts and analytical problems with marine samples. Mar Chem 41:243-252

Percival E, Rahman MA, Wiegel H (1980) Chemistry of the polysaccharides of the diatom Coscinodiscus nobilis. Phytochemistry 19:809-811

Sakugawa H, Handa N (1985) Isolation and chemical characterization of dissolved and particulate polysaccharides in Mikawa Bay. Geochim Cosmochim Acta 49:1185-1193

Skoog A, Benner R (1997) Aldoses in various size fractions of 
marine organic matter: Implications for carbon cycling. Limnol Oceanogr 42:506-518

Smestad B, Haug A, Myklestad S (1975) Structural studies of the extracellular polysaccharide produced by the diatom Chaetoceros curvesetus Cleve. Acta Chem Scand B 29: $337-340$

Stoderegger K, Herndl GJ (1998) Production and release of bacterial capsular material and its subsequent utilization by marine bacterioplankton. Limnol Oceanogr 43: $877-884$

Tanoue E (1995) Detection of dissolved protein molecules in oceanic waters. Mar Chem 51:239-252

Editorial responsibility: Otto Kinne (Editor),

Oldendorf/Luhe, Germany
Thingstad F, Billen G (1994) Microbial degradation of Phaeocystis material in the water column. J Mar Syst 5: $55-65$

Tranvik L (1994) Colloidal and dissolved organic matter excreted by a mixotrophic flagellate during bacterivory and autotrophy. Appl Environ Microbiol 60:1884-1888

Williams P, Gordon L (1970) Carbon-13:Carbon-12 ratios in dissolved and particulate organic matter in the sea. DeepSea Res 17:19-27

York WS, Darvill AG, McNeil M, Stevenson TT, Albersheim $P$ (1985) Isolation and characterization of plant cell walls and cell wall components. Meth Enzymol 118:3-40

Submitted: October 12, 1998; Accepted: March 29, 1999

Proofs received from author(s): September 1, 1999 